\title{
Targeted Management of Labor Productivity for Sustainable Development of Enterprises
}

\author{
Marina Simonova ${ }^{1, *}$, Vladlena Grikhno ${ }^{2,3}$ and Natalya Nikolashina ${ }^{1}$ \\ ${ }^{1}$ Samara State Technical University, Samara, Russia \\ ${ }^{2}$ Samara State Economic University, Samara, Russia \\ ${ }^{3}$ G.V. Plekhanov Russian University of Economics, Moscow, Russia
}

\begin{abstract}
Study purpose: scientific substantiation of an innovative approach to economic concepts related to productivity and determination of the location of labor productivity in the product value added chain to ensure sustainable development. Methodology: the development of a model for creating added value with the allocation of a stage in it at which human labor is used, allowed the author to determine the possibility of setting goals for the short, medium and long term for various stages of production. The article substantiates the need to divide the principles of calculating labor productivity by stages of added value creation, highlighting the stage of creating innovations. As a result of the decomposition of the goals of the production system, the author comes to the conclusion that there is a need for more accurate positioning of labor productivity in the value-added chain and the transition from setting the goal of increasing labor productivity to solving a problem that ensures an increase in the efficiency and stability of the entire economic system. As a result of the research, a model for coordinating the growth of labor productivity and investment directions to achieve high rates of productivity and stability of the economic system has been drawn up.
\end{abstract}

\section{Introduction}

Labor productivity is one of the most significant factors affecting economic growth and sustainable development at both the macroeconomic and microeconomic levels [9]. That is why in recent years such importance has been attached to the growth of labor productivity through the adoption of appropriate state programs and projects [3]. For each enterprise, the growth of labor productivity becomes an important element in reducing the cost of production, improving its quality, and reducing production times [4]. Herewith, the current growth rates of labor productivity cannot meet the needs of the economy and ensure the sustainability of growth [7] and the reason here, in our opinion, is not only in production or economic reasons, but also in the change in labor accents in the production cycle, the absence of modern interpretation of the place and role of labor productivity in the system of industrial and economic relations. The use of the target approach [6] to achieve the desired result has already become a ubiquitous management practice, however, when setting goals for

\footnotetext{
* Corresponding author: est-samara@mail.ru
} 
increasing labor productivity, production goals and objectives are often substituted due to inaccurate positioning of labor productivity in the management system, which leads to a decrease in overall production results and has the following negative consequences:

- inaccurate definition of the goals and objectives of labor productivity in general negatively affects the results of activities to increase productivity;

- ambiguity in the use of standard indicators of labor productivity in innovative and service companies

- ambiguity of the need to increase the automation of processes in service companies.

Our research is empirical in nature and may serve as the beginning of research work to develop answers to the questions posed. The purpose of the work is to model a management system for sustainable growth of labor productivity in the general system of creating added value of a product based on a decomposition of goals and objectives for management levels, as well as to develop a strategic vision for productivity growth using traditional and progressive technologies. This requires a more accurate understanding of the relationship between the concepts of "labor productivity" and "productivity of the economic system", to determine the production area with the highest added value, to identify areas of responsibility for various management levels, to develop a strategic model for the growth of labor productivity pursuant to traditional and innovative technological schemes.

\section{Research Methodology}

The study of the concept of "labor productivity" has rather deep historical roots and, nevertheless, does not lose its relevance in our time, since we are witnessing a significant transformation of the labor process throughout the entire cycle of creating added value of a product - from idea to consumption. There is a redistribution of employment by stages, the concentration of the use of living labor in this cycle changes, when in the traditional scheme of production of products adopted in the industrial era, the bulk of employed employees fell on the stage of direct production of products, that is, the largest number of employed employees were in workshops and in production sites. In the postindustrial era, when living labor is increasingly being replaced by automated and robotic industries, a person is displaced from production, products of past labor are replaced, and employment increases at other stages of added value creation (Fig. 1).
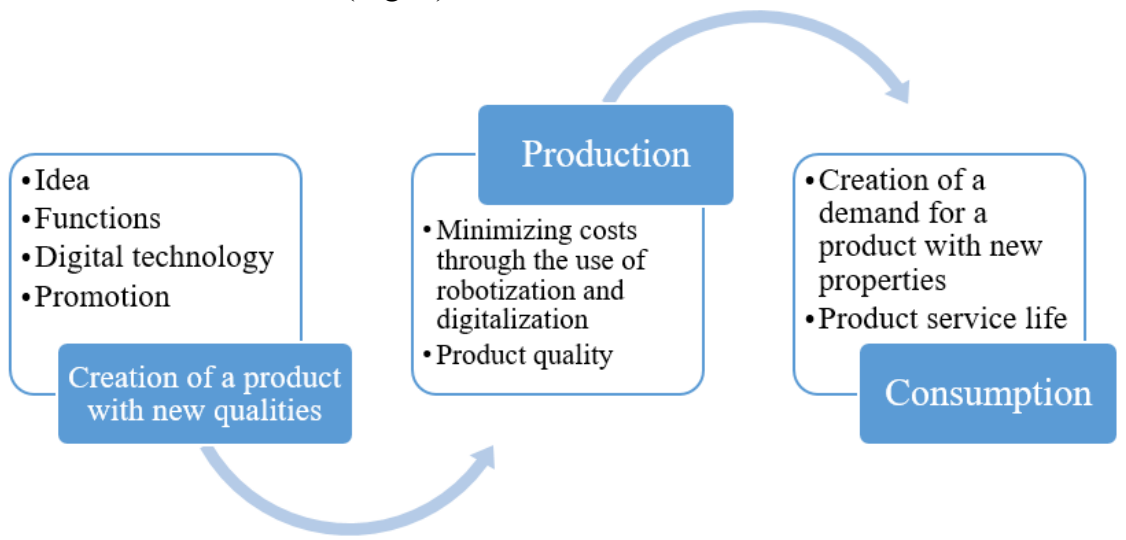

Fig. 1. Modeling the process of emerging value added products. Source: developed by the authors.

Labor productivity growth is concentrated at the stage of production and it is here that one may see the results of increasing labor productivity by reducing costs and timing of the production cycle. Herewith, the growth of labor productivity does not in any way affect 
productivity at the first in the last stages of creating added value. That is, even with a significant increase in labor productivity at the stage of production, general productivity growth may not occur, the manufactured products may remain unclaimed for various reasons - from changes in consumer preferences to crisis phenomena in the economy as a whole. This is one of the reasons for the increasing importance of the first and last stages of the value added cycle. Labor productivity growth occurs with the greatest value added to the product at the stage of creating innovative products with new consumer qualities. The stage of production of products becomes a consequence of the technology developed at the first stage of creating a product and an increase in labor productivity on it should be emphasized in the field of labor organization and cannot give a significant increase in labor productivity.

\section{Study Results}

In addition to increasing the importance of the stages of product creation and consumption for increasing productivity, there is also a quantitative redistribution of jobs by stages while maintaining the general trend towards a reduction in employment with an increase in labor productivity [11]. For employment planning, it is necessary to consider the change in the structure of employment associated with the redistribution of living labor in the production chain. The reduction in employment at the production stage is partially quantitatively compensated for at the stages of creating products with new qualities and consumption, with a simultaneous increase in requirements for the qualitative characteristics of the labor force at all stages.

Herewith, a fairly large proportion of manufacturing enterprises in our country operate pursuant to industrial principles, on which gradual modernization is still ongoing. For this category of industries, the significance of the production stage and the increase in labor productivity are of significant importance, which may affect the cost of production and the timing of production, but this increase in labor productivity will not have long-term prospects. This increase in labor productivity may be achieved in the short term and does not require significant investment. To ensure higher growth rates of labor productivity, it is necessary to invest in the development of the first and last stages of creating added value [10], however, these investment costs will be much higher, but the effect from them may be expected at a much higher level (tab. 1).

Table 1. Structuring target needs while creating added value. Source: developed by the authors.

\begin{tabular}{|c|c|c|c|}
\hline & Short term period & $\begin{array}{c}\text { Medium term } \\
\text { period }\end{array}$ & $\begin{array}{c}\text { Long-term } \\
\text { period }\end{array}$ \\
\hline $\begin{array}{c}\text { The idea of a new consumer } \\
\text { value, the formation of market } \\
\text { needs }\end{array}$ & & & $\checkmark$ \\
\hline Production & $\checkmark$ & $\checkmark$ & \\
\hline $\begin{array}{c}\text { Consumption, sales, product } \\
\text { promotion }\end{array}$ & & $\checkmark$ & $\checkmark$ \\
\hline
\end{tabular}

The existing methods for calculating labor productivity, in our opinion, are mainly applicable to existing industries operating pursuant to industrial principles, while an increasing number of enterprises are either undergoing a complete modernization or are being built anew with new technological approaches for the production of innovative products. In such a holistic system, from idea to consumption, it is only conditionally possible to apply standard methods for calculating labor productivity, as well as at individual stages, the content of labor at which has changed significantly due to the innovativeness of the processes. 
In our view, it is necessary to divide the principles of calculating labor productivity by stages of creating added value (Fig. 2).

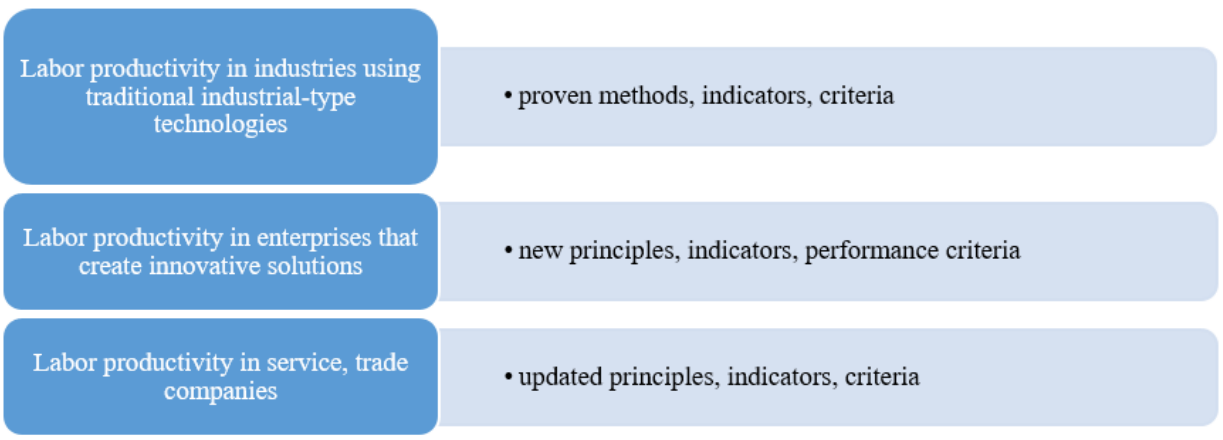

Fig. 2. The need to separate the principles for calculating labor productivity by stages of added value creation. Source: developed by the authors.

Indicators, parameters and criteria of labor productivity should be different for each stage, depending on the specifics of the stage and the typical type of activity, significantly different in parameters from industrial production, e.g., in the service sector, sales, agricultural labor [12]. Automation of processes in which the customer contacts the seller also raises questions about other criteria, but here, too, it is necessary to move from standard methods for determining labor productivity to updated principles that consider new realities [13].

Based on the logic of the sequence of stages of creating added value, it is possible to single out the stage of creating a product with new qualities and put it as parallel to the production process, highlighting common goals and dividing it into management levels to define tasks (Fig. 3).

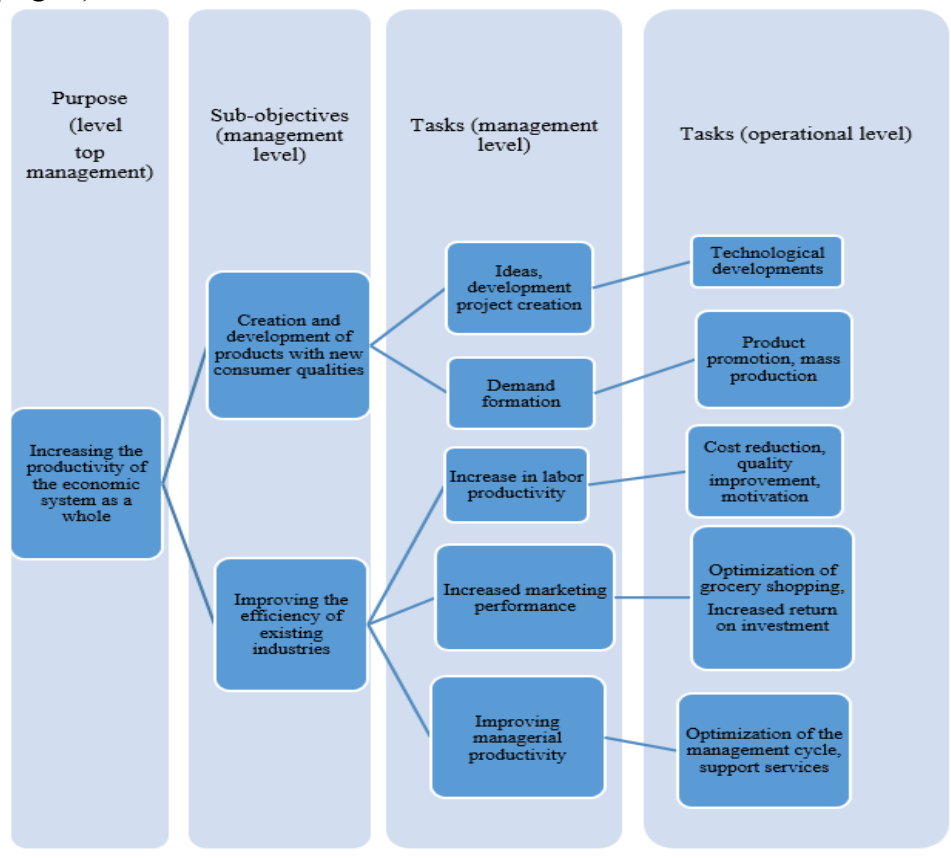

Fig. 3. The need to separate the principles for calculating labor productivity by stages of added value creation. Source: developed by the authors. 
If we consider the entire cycle from the idea to the consumption of the final product, then from a managerial point of view, the location of the element "increasing labor productivity" is at the level of management of the production enterprise and refers to the tasks, and not to the goals of the activity, which in many cases contradicts the established practice, when the increase labor productivity acts as the ultimate goal. The goals are set at the level of the owners and top management of the enterprise and, in general, may be characterized as an increase in the productivity of the entire economic and production system as a whole, which is calculated in the traditional way as the ratio of income to expenses [5]. In our opinion, there is a confusion of concepts and correction is required, not only terminological, but also substantive, when a more accurate division of economic approaches by means and methods of calculation is necessary. Such a substitution of concepts leads to an incorrect setting of goals and objectives not only at the enterprise level, but in government programs, the use of ineffective mechanisms, an irrational distribution of forces and resources, which ultimately does not give the desired result. The decomposition of goals and objectives allows us to see a complex of management elements that affect the increase in the overall productivity of the entire economic system to no less than labor productivity - these are managerial productivity, marketing, organizational and other types of productivity that may both enhance the effect of growth in labor productivity and minimize it. Therefore, we consider it necessary, when calculating the productivity of the economic system, to consider labor productivity as one of the factors influencing the achievement of the final goal, but not decisive, and the significance of this factor should differ when calculating productivity in industries using traditional and innovative technologies.

\section{Result Discussion}

Pursuant to scientists [1], the slowdown in economic productivity growth began to decline throughout the world at the end of the twentieth century. This applies primarily to developed countries, which shows the technological and institutional limit of development pursuant to existing technologies [2], when productivity constraints are not at the stage of production, but at the stage of consumption. A decrease in the growth rate of labor productivity is also observed in Russia [15], demonstrating rare increases, e.g., in 2006 and mostly negative dynamics, although the average growth from 2003 to 2019 amounted to $2.0 \%$, there is a steady downward trend. Herewith, various reports and programs utilize the concept of the productivity of labor meaning the productivity of the entire system, but not the real productivity of living labor at the production stage. In this case, the discrepancy between terminology and content leads to a substitution of goals and objectives of activities, unreliable use of tools, overestimated expectations from investments and capital investments in fixed assets at industrial enterprises, which may only lead to a limited increase in labor productivity, but in a fairly close time period. Investments in the process of creating products with new consumer qualities cannot give a quick effect, however, after several years, which are necessary for development from an idea to debugging a technology and bringing a product to a consumer, the productivity of the entire economic system may many times exceed the productivity of investments in traditional technologies.

An increase in labor productivity in industrial-type industries in the short term should be combined with investments in the innovative process of developing and creating products with new qualities, and only in this case it is possible to obtain a stable increase in the productivity of the entire economic system both in the short and long term. In addition, it is necessary to consider the change in the structure of employment during the transition to new technologies and design employment already considering these changes [14]. In a strategic perspective, it may be assumed an increase in the labor market share of specialists with a 
research and innovative nature of labor and specialists in promotion, engineering and service, while reducing the share of employees directly involved in the production process.

\section{Conclusions}

Determination of the place and role of labor productivity as a managerial element in the system of setting goals of the production system as an integral process of sustainable growth contributes to a more accurate characterization of the content of the concept, since a distorted goal setting in the form of an increase in labor productivity instead of an increase in the productivity of the economic system has become widespread. It was revealed that the growth of labor productivity belongs to the tasks at the middle management level, which, along with the growth of managerial, organizational, marketing, financial and other types of productivity, has an impact on the overall productivity growth of the economic system.

Unlike growth in labor productivity, the productivity of the entire system may be increased in the medium and long term through investments in research and development and marketing technologies, while in the short term, results may be obtained from low investment measures to increase the growth rate of labor productivity in production using traditional technologies. Such low investment measures include the optimal organization of labor in production, cost reduction, advanced training, skills, employee motivation and other wellknown tools [8]. Herewith, investments in the creation of new creative products provide the highest added value.

The development of a management model for a sustainable increase in labor productivity in terms of goals and a strategic model of the productivity results of the entire system, depending on the investment process, made it possible to develop a forecast of stable productivity growth based on the combination and parallelism of the processes of creating innovations and manufacturing products. The approach to labor productivity as an element in the value-added chain made it possible to identify new trends in the nature and structure of employment, characterized by a reduction in production personnel due to digitalization and robotization of technological lines and an increase in the need for employees with creative, scientific and design competencies. It is also possible to predict an increase in the share of the labor market of service personnel, providing communication with consumers with the growth of requirements for the quality of the workforce at all levels and at all stages.

The allocation of the innovation process and the consumption process in a separate stage involves a change in the principles of calculating labor productivity, depending on the nature of labor activity, changes in indicators and performance criteria. In further research, it is necessary to clarify approaches to the development of labor economics, develop and scientifically substantiate each stage of creating added value pursuant to updated principles, which determines the prospects for scientific research.

\section{References}

1. V.A. Vinokurova, Int. J. of Humanities and Natural Sciences 3-2, 18 (2019)

2. V.N. Knyaginin, New Technological Revolution: Challenges and Opportunities for Russia. Expert and analytical report, 136 p. (Moscow: Center for Strategic Research, 2017)

3. B.L. Lavrovsky, M.V. Khairullina K.N. Volosskaya A.V. Chuvaev, ECO 6(552), 111 (2020)

4. A.Yu. Misailov A.M. Davydov D.M. Davydov, Bulletin of higher educational institutions. - Technology of the textile industry 1 (385), 33 (2020)

5. N.N. Mikheeva, Region: Economics and Sociology 2 (86), 86 (2015) 
6. YU.V. Rostovtseva, Economic Bulletin of Rostov State University 5 (1-2), 267 (2007)

7. YU.V. Simachev, M.G. Kuzyk, A.A. Fedyunina, M.A. Yurevich, J. of the New Economic Association 4 (48), 205 (2020)

8. A.A. Fedchenko, Labor Economics 3 (1), 41 (2016)

9. M.V. Cherkasov, A.N. Grachev, V.A. Lapidus, Standards and quality 5, 72 (2021)

10. D. Acemoglu, P. Restrepo, Artificial Intelligence, Automation and Work, 43 p. (Cambridge: NBER Working Papers, National Bureau of Economic Research, Inc., 2018). https://www.nber.org/papers/w24196.pdf

11. D. K. Datta, J. P. Guthrie, P. M. Wright, Academy of Management J. 48(1), 135 (2005)

12. M. Duarte, D. Restuccia, Quarterly J. of Economics 125(1),129 (2010)

13. R. T. Rust, M.-H. Huang, Journal of Marketing 76(2), 47 (2012)

14. M.V. Simonova, L.V., Sankova, F.I. Mirzabalaeva, Employment in innovation production networks: regional sample. GCPMED 2018, International Scientific Conference "Global Challenges and Prospects of the Modern Economic Development", 1341 (Springer: Future Academy, 2018)

15. Trading Economics. Current values, historical data, forecasts, statistics, graphs and $\begin{array}{llllll}\text { economic calendar } & - & \text { Russia } & - & \text { Productivity. }\end{array}$ https://tradingeconomics.com/russia/productivity 